\title{
The Association between Female Genital Mutilation and Sexual Dysfunction during Pregnancy: a Pilot Study
}

\author{
Eman E. Ebrahim ${ }^{1}$, Marwa M. Ahmed ${ }^{1}$, Rasha S. Alkholy ${ }^{1}$, Marwa S. Said ${ }^{1 *}$ \\ ${ }^{1}$ Department of Family Medicine, Cairo University, Egypt
}

\begin{abstract}
:
Background: Female sexual dysfunction is considered as one of the ignored consequences associated with female genital mutilation. Female genital mutilation is estimated to be done for 200 million females in Africa and Asia. Objectives: This study aimed at assessing the effect of female genital mutilation on sexual dysfunction among pregnant females. Methods: This is a cross-sectional study conducted over a 6-month period. Participants were recruited from 3 outpatient clinics at Kasr Alainy Faculty of Medicine, Cairo University. A total of 206 eligible pregnant females were asked to fill El-Gilany Socio-economic Status Scale and the Arabic version of the Female Sexual Function Index. Then, the individual domains and total scores were calculated. Results: The results showed that female genital mutilation among women is inversely proportionate to their level of education $(P$-value 0.02$)$. Female Sexual Function Index results revealed that the most affected domain of sexual dysfunction was the lubrication and satisfaction domains. However, no statistically significant difference between the two groups in all other domains or the total Female Sexual Function Index scores. Conclusion: The current study concluded that there is no difference in sexual function between circumcised and non-circumcised pregnant females regarding prevalence and indicators.
\end{abstract}

Keywords: Female genital mutilation, Female sexual dysfunction, Pregnancy.

\section{Introduction}

Globally, female genital mutilation (FGM), also known as female circumcision (FC), is a public health concern affecting girls and women. ${ }^{(1)} \mathrm{FGM}$ is any procedure to partially or totally remove external female genitalia or any injury to the female genital organs without medical indications. ${ }^{(2)}$

FGM is concentrated in the developing countries, mostly in Asia, sub-Saharan Africa, and the Middle East. ${ }^{(3)}$ It is usually done to girls between infancy and adolescence, and sometimes done to adult females. More than 3 million girls are at risk for FGM every year. Moreover, it is estimated that around 30 countries, alive 200 million girls and females have been affected by this procedure. ${ }^{(2)}$ According to the 2015 Egyptian Health Issues Survey (EHIS), the female genital mutilation prevalence among females aging from 15 to 49 years in Egypt is 87\%. ${ }^{(4)}$

The procedure is mostly done using the same tools for many girls. The operators can range from circumcisers to midwives and birth attendants. A sterile environment and anesthetics are not available. The healing process is aided by herbs or animal excrement. ${ }^{(3)}$

Female Genital Mutilation has deep cultural, sociological, and traditional roots

*Corresponding author: marwapay@ hotmail.com

(c) This article is an open access article distributed under the terms and conditions of the Creative Commons Attribution (CC BY) license (http://creativecommons.org/licenses/by/4.0/) 
with no known health benefits. ${ }^{(3,5)}$ The consequences include both short and longterm physiological and psychological complications ${ }^{(6)}$ such as severe bleeding, urinary problems as dysuria and recurrent urinary infections, cysts, and infections. ${ }^{(3)}$ Common delayed complications include psychological problems as posttraumatic stress disorder, anxiety, depression, and sometimes psychoses. ${ }^{(3)}$

Disparities in obstetric outcomes between women with FGM and those without FGM are clear. FGM has a negative impact on many obstetric events including prolonged labor, instrumental delivery, obstetric lacerations, obstetric hemorrhage, and difficult delivery as well as increased risk of newborn deaths. ${ }^{(3,7)}$

Among the complications that are not always reported of FGM is female sexual dysfunction (FSD). Female sexual dysfunction presents with pain during intercourse, reduced sexual desire as well as reduced sexual satisfaction. ${ }^{(7)}$

The prevalence of FSD after FGM ranges from $25 \%$ to $63 \%$ depending on the type of dysfunction and the studied population. It is not surprising that women with FGM, especially with the abovementioned complications, will have problems with sexual intercourse. ${ }^{(8)}$

The management of these complications costs around 1.4 billion USD per year in 27 high prevalence countries. (2) Data on mortality are unavailable; however, it is estimated that 1 case every 500 circumcisions dies. ${ }^{(9)}$

This study was carried out in Egypt similar to many studies which have been conducted to detect the prevalence, sexual dysfunction, and obstetric complications associated with FGM. However, scarce studies have been conducted on female sexual dysfunction among pregnant females with FGM. The topic is under-reported and often overlooked. The present study aimed to identify the effect of FGM on sexual dysfunction among a sample of pregnant females.

\section{Methods:}

\section{Research design and setting:}

This is a cross-sectional analytical study conducted over a period of 6 months Participants were recruited from 3 outpatient clinics at Kasr Alainy Faculty of Medicine, Cairo University, including the Gynecology and Obstetrics clinic, the Family Medicine clinic, and the Antenatal clinic.

\section{Sample size estimation:}

Based on a study by the Egyptian Ministry of Health and Population, ElZanaty and associates reported that the prevalence of FSD among Egyptian females during pregnancy was $68.8 \% .^{(13)}$ Considering a total population of 
approximately 500 pregnant females attending any of the specified outpatient clinics over a 3-month period, $80 \%$ power, $5 \%$ significance level, a minimal sample size of 204 participants was required to achieve the study objectives (per Epi Info 7).

Two hundred and eighteen pregnant females fulfilling the eligibility criteria were approached to take part in the study. Only 12 of them refused to complete the interview. The remaining 206 pregnant females gave informed consent and successfully completed the interview, rendering a response rate of $95 \%$.

\section{Inclusion criteria:}

All pregnant females aging from 18 to 45 years and agreed to participate in the study, regardless of their gestation status, were invited to take part in the study.

\section{Exclusion criteria:}

Participants were excluded if they had severe neurologic or sensory impairments. In addition, females having severe mental disorders which could impair their ability to provide informed consent were excluded.

Recruitment process: Pregnant females attending the specified outpatient clinics during working hours (from 8 a.m. to 2 p.m.) 3 days per week over a period of 6 months were recruited. The study was introduced to these females while they were in the clinic's waiting area.
Interested participants were then checked for eligibility and given more information about the study including the interview process and procedures taken to protect confidentiality. Participants were asked to provide consent before starting the interview. Each interview lasted for approximately 20 to 30 minutes.

\section{Data collection tools:}

1. Socio-demographic and medical data: This part included the participants' age, pregnancy trimester, and education. The medical data included questions about any chronic disease that may cause sexual dysfunction as diabetes mellitus, cardiovascular diseases, bronchial asthma, arthritis, and urinary incontinence. Also, it included questions about sexual disorders that may cause sexual dysfunction as vaginismus, vaginitis, vulvovaginal atrophy, vulvovaginal masses, or prolapse.

2. El-Gilany et al. (2012) Socio-Economic Status (SES) scale ${ }^{(10)}$ : This scale was used to assess participants' SES. The scale includes 7 domains (education and cultural, family, economic, occupational, family possessions, home sanitation, and health care) with a total score of 84 . SES scores were classified into 3 subsets: low $(\leq 42)$, middle (43-63), and high (64-84) levels. 
3. The Arabic version (Anis et al., 2011) (11) of the Female Sexual Function Index (FSFI; Rosen et al., 2000) ${ }^{(12)}$ : The Arabic version of FSFI scale was previously examined psychometrically in an Egyptian population and proved to possess reasonable reliability and validity. ${ }^{(11)}$

The FSFI is a 19-item self-reporting scale that assesses sexual function over the past 4 weeks and yields scores covering 6 domains: desire, arousal, lubrication, orgasm, satisfaction, and pain. Sexual activity was graded as good if FSFI was 30 or above, intermediate if FSFI was 22-29, and poor if FSFI was $<22$.

Analysis and reporting of data: All completed questionnaires were assessed for completeness and consistency. Pre-coded data were digitalized using the Microsoft Office Excel Program for Windows, 2010. Data entry took place at the end of each working day. Then, the data were double checked and transferred to the Statistical Package of Social Science, Version 21 (SPSS-V 21) for analysis using the appropriate methods (SPSS Inc., Chicago, IL).

Numerical data were described as mean and standard deviation and range. Categorical data were described as numbers and percentages. Comparisons between the
2 groups for normally distributed numeric variables were conducted using the Student's t-test. Comparisons between categorical variables were conducted using the Chi square test.

\section{Ethical considerations:}

This study was reviewed and approved by the research and ethical committee in Kasr Alainy, Faculty of Medicine, Cairo University after being approved by the Family Medicine department including the research committee before the beginning of the study.

Informed consent was taken from each participant before interview. Each participant was interviewed individually after explaining the purpose of the study and assurances of confidentiality were given.

\section{Results:}

The results of the current study shows that among 206 pregnant participants, 97 females had FGM and 109 did not. Most of the study participants were in the third trimester; $43.29 \%$ of the females in the group with FGM and $51.37 \%$ in the group without FGM.

The socio-demographic characteristics of the study population shows that most of the participants were middle-aged females between 25-30 years, of middle social class, and received a high level of education. There is no statistical significance between both groups considering age, education, 
socioeconomic class, chronic diseases, or sexual diseases.

However, regarding the level of education, high education level is $57.73 \%$ for the group with FGM versus $64.22 \%$ for those without FGM which is statistically significant with $\mathrm{p}$-value 0.02 as shown in Table (1).

The most affected sexual function domain according to the FSFI questionnaire is the lubrication and satisfaction domains where in the group with FGM, the lubrication domain was $4.12 \pm 1.53$ versus $4.11 \pm 1.68$ in the group without FGM.

The satisfaction domain in the group with FGM was $4.06 \pm 1.54$ versus $4.10 \pm 1.49$ in the group without FGM. The least affected domain in the FGM group was the arousal domain $3.10 \pm 1.47$, while the least affected domain in the non-FGM group is the pain domain $3.32 \pm 1.12$ as shown in Table (2).

There is no statistically significance difference between the two groups in all the domains as well as the total FSFI score as shown in Table (2).

Regarding the sexual satisfaction before pregnancy, $35.05 \%$ with FGM and $41.28 \%$ without FGM are unsatisfied with the sexual relation and these results have no change during pregnancy where $34.02 \%$ with FGM and $40.36 \%$ without FGM are unsatisfied with the sexual relation was no statistically significant difference as seen in Table (3).

\section{Discussion:}

It is estimated that all around the world, FGM has been done to about 100-140 million regardless health risks and governmental punishments. (14) Very few researches studied the psychological and sexual functions of females who have been mutilated because the society does not consider it as an important issue. ${ }^{(9)}$

Female sexual dysfunction is any complaint affecting any part of the sexual function including desire, arousal, lubrication, satisfaction, orgasm, sexual pain, or any personal distress during the sexual act. ${ }^{(15)}$ The current study probes the impact of FGM on the sexual function of pregnant females.

The results of our study are partially consistent with Ahinkorah et al 2020 who used pooled data from the current Demographic and Health Surveys (DHS) conducted between January 1, 2010, and December 31, 2018 in 12 countries in Sub Saharan Africa.

They concluded that FGM is inversely proportionate to the level of education (16) where the prevalence of FGM decreased in females with high level of education.

However, Andro et al ${ }^{(17)}$ who investigated in their review the prevalence of FGM and its variation over time in 
different regions of the world as well as the current determinants of the practice and its effects on health and sexuality stated that education only cannot decrease FGM, especially that it is usually done before school in girls who don't understand and cannot refuse the practice, but it may affect the family who take the decision.

In contrary to Ahinkorah et al 2020, our study concluded that age and social class has no effect on FGM. This can be explained by the study sample where most of the study participants were of middle class and middle age. ${ }^{(16)}$

Our study showed that FGM has no effect on the sexual function of pregnant females in contrary to a study done by Alsibiani and Rouzi who studied 130 sexually active women with FGM and other 130 sexually active women without FGM at a tertiary referral university hospital in Jeddah, Saudi Arabia.

They found that there was no statistical significance regarding desire or pain; however, a statistical significance was found in the other domains including arousal, lubrication, orgasm, and satisfaction, as well as the overall sexual function score between females with and without FGM. ${ }^{(18)}$

Regarding the total FSFI score between females with and without FGM, the results of our study were similar to the results of
Abdulcadir et al. ${ }^{(19)}$ who recruited from the University hospital of Geneve 15 women with FGM involving cutting of the clitoris and 15 uncut women as a control group.

Then, they had pelvic magnetic resonance imaging and completed FSFI questionnaire. The authors of this study found that FGM does not affect the female sexual function and explained that a smaller clitoris could lead to better perception of the female genitalia and better sexual function.

Our study compared the sexual satisfaction of the participants before and during the current pregnancy in the two groups (with and without FGM) and found that there was no statistical significance.

These results are similar to what was concluded by Mobasher et al 2019 who conducted their study at Assiut University Hospital, Egypt and reported no statistical significance in the sexual function between pregnant and non-pregnant females regarding the prevalence and indicators. ${ }^{(20)}$

However, this is opposite to Serati et al 2010 who analyzed 48 PubMed research that examining female sexual function during pregnancy in the period between 1960 and $2009 .^{21}$

Their conclusion was that female sexual function decreases significantly during pregnancy, mainly during the third trimester. However, this analysis was done 
before the appearance of validated tools to assess female sexual function.

\section{Study limitation:}

The results can not be generalized owing to the small sample size that makes the cause and effect unclear except after randomized control trials.

\section{Conclusion:}

The current study concluded that there was no difference in sexual function between circumcised and non-circumcised pregnant females in terms of prevalence and indicators.

Accordingly, further research and more studies with larger sample size including pregnant and non-pregnant females would be needed to investigate possible association between FGM and sexual dysfunction during pregnancy and study the long-term effects that could result from FGM. Specific laws to ban female genital mutilation should be issued and awareness programs should be conducted to increase people's awareness of FGM.

Conflict of interest: The authors state that they have no conflict of interests.

Funding: There has been no financial support for this work.

Acknowledgement: Sincere gratitude to the patients who participated in this work.

\section{References:}

1- UNICEF. UNICEF'S data work on FGM/C, 2016. Available at: https://www.unicef.org/media/files/FGM C_2016_brochure_final_UNICEF_SPR EAD.pdf (Accessed on 27th March 2021)

2- World Health Organization (WHO). Female genital mutilation, 2020. Available at: https://www.who.int/newsroom/fact-sheets/detail/female-genitalmutilation (Accessed on 27th March 2021)

3- Klein E, Helzner E, Shayowitz M, et al. Female Genital Mutilation: Health Consequences and Complications-A Short Literature Review. Obstet Gynecol Int. 2018; 2018:7365715.

4- UNICEF. UNICEF'S data on Female genital mutilation in Egypt Recent trends and projections. available online at : https://data.unicef.org/resources/femalegenital-mutilation-in-egypt-recenttrends-and-projections/ (Accessed on $7^{\text {th }}$ August 2021)

5- Odemerho BI, Baier M. Female genital cutting and the need for culturally competent communication. Journal for Nurse Practitioners. 2012; 8(6): 452457.

6- Chibber R, El-Saleh E, El Harmi J. Female circumcision: obstetrical and 
psychological sequelae continue unabated in the 21 st century. $J$ Matern Fetal Neonatal Med. 2011; 24(6): 833836.

7- Berg RC, Underland V. The obstetric consequences of female genital mutilation/cutting: a systematic review and meta-analysis. Obstet Gynecol Int. 2013; 2013:496564.

8- Elneil S. Female sexual dysfunction in female genital mutilation. Tropical Doctor. 2016; 46(1): 2-11.

9- Reyners M. Health consequences of female genital mutilation. Reviews in Gynaecological Practice. 2004; 4(4): 242-251.

10- El-Gilany A., El Wehady A., El Wasify M. Updating and validation of the socioeconomic status scale for health research in Egypt. East Mediterr Health J. 2012.18 (9): 962-8.

11- Anis T, Gheit S, Saied H, Kherbash S. Arabic Translation of Female Sexual Function Index and Validation in an Egyptian Population. The journal of sexual medicine. 2011. 8. 3370-8.

12- Rosen R, Brown C, Heiman J, et al. The Female Sexual Function Index (FSFI): A multidimensional self-report instrument for the assessment of female sexual function. J Sex Marital Ther 2000; 26: 191-208.
13- Ministry of Health and Population (Egypt), ElZanaty and associates (Egypt), ICF international: Egypt Demographic and Health Survey. Cairo, Egypt and Rocckville. Maryland, USA: Ministry of Health and population and ICF international; 2014 p.185-195.

14- Female Genital Mutilation: Report of a Technical Working Group, Geneva, 17-19 July 1995. Family and Reproductive Health. World Health Organization, Geneva; 1996.

15- Raina R., Pahlajani G., Khan S., et al. Female sexual dysfunction: classification, pathophysiology, and management. Fertil Steril. 2007; 88: 1273- 1284.

16- Ahinkorah BO, Hagan JE, Ameyaw EK, et al. Eric Torgbenuand Thomas Schack. Socio-economic and demographic determinants of female genital mutilation in sub-Saharan Africa: analysis of data from demographic and health surveys. Reprod Health 2020; 17:162.

17- Andro A, Lesclingand M, Grieve M, et al. Female genital mutilation. Overview and current knowledge. Population. 2016; 71(2): 217-296.

18- Alsibiani SA, Rouzi AA. Sexual function in women with female genital 
mutilation. Fertility and sterility, 2010; 93(3): 722-724 .

19- Abdulcadir J, Botsikas D, Bolmont M, Bilancioni A, Djema D A, Demicheli FB, Petignat P: Sexual anatomy and function in women with and without genital mutilation: a cross-sectional study. The journal of sexual medicine. 2016; 13(2): 226-237.
20- Mobasher A, Ismail SA, Habib D, Abu-Taleb D, et al. The effect of pregnancy on female sexual function: a cross-sectional study J Curr Med Res Pract, 2019; 4(2): 170-173.

21- Serati M, Salvatore S, Siesto G, et al. Female sexual function during pregnancy and after childbirth. J Sex Med. 2010; 7(8): 2782-90.

Table (1): Relation between the sociodemographic characteristics and female genital mutilation

\begin{tabular}{|c|c|c|c|c|c|}
\hline \multirow{4}{*}{$\begin{array}{l}\text { Variables } \\
\text { Age groups: } \\
\text { - } 18-25\end{array}$} & \multicolumn{4}{|c|}{ FGM } & \multirow[t]{3}{*}{$P$-value } \\
\hline & \multicolumn{2}{|c|}{$\begin{array}{l}\text { Not Done } \\
(\text { No.=109) }\end{array}$} & \multicolumn{2}{|c|}{$\begin{array}{c}\text { Done } \\
(\text { No.=97) }\end{array}$} & \\
\hline & No. & $\%$ & No. & $\%$ & \\
\hline & 15 & 13.76 & 12 & 12.37 & \multirow{5}{*}{0.53} \\
\hline$\cdot 25-30$ & 58 & 53.21 & 55 & 56.70 & \\
\hline - $\quad 30-35$ & 23 & 21.10 & 23 & 23.71 & \\
\hline - $35-40$ & 11 & 10.09 & 4 & 4.12 & \\
\hline - $40-45$ & 2 & 1.83 & 3 & 3.09 & \\
\hline $\begin{array}{l}\text { Education: } \\
\text { - Illiterate }\end{array}$ & 5 & 4.58 & 1 & 1.03 & \multirow{4}{*}{0.02} \\
\hline - Basic & 20 & 18.34 & 19 & 19.58 & \\
\hline - Secondary & 14 & 12.84 & 21 & 21.64 & \\
\hline - High & 70 & 64.22 & 56 & 57.73 & \\
\hline $\begin{array}{l}\text { Social class: } \\
\text { - Low }(<42)\end{array}$ & 24 & 22.01 & 19 & 19.58 & \multirow{3}{*}{0.19} \\
\hline - Middle (43-63) & 82 & 75.22 & 75 & 77.31 & \\
\hline - High (64-84) & 3 & 2.75 & 3 & 3.09 & \\
\hline $\begin{array}{l}\text { Chronic diseases: } \\
\text { - Yes }\end{array}$ & 6 & 5.50 & 3 & 3.09 & \multirow[t]{2}{*}{0.40} \\
\hline - No & 103 & 94.49 & 94 & 96.90 & \\
\hline $\begin{array}{l}\text { Sexual diseases: } \\
\text { - Yes }\end{array}$ & 5 & 4.58 & 3 & 3.09 & \multirow[t]{2}{*}{0.35} \\
\hline - No & 104 & 95.41 & 94 & 96.90 & \\
\hline
\end{tabular}


Table (2): Relation between FSD and FGM

\begin{tabular}{|l|c|c|c|}
\hline \multirow{2}{*}{\multicolumn{1}{|c|}{ FSFI domains }} & \multicolumn{2}{|c|}{ FGM } & \multirow{2}{*}{ P value } \\
\cline { 2 - 3 } & $\begin{array}{c}\text { Not done } \\
\text { No.=109 }\end{array}$ & $\begin{array}{c}\text { Done } \\
\text { No.=97 }\end{array}$ & \\
\cline { 2 - 3 } - Desire domain & $3.45 \pm 1.16$ & $3.29 \pm 1.18$ & 0.32 \\
\hline - Arousal domain & $3.34 \pm 1.55$ & $3.10 \pm 1.47$ & 0.27 \\
\hline - Lubrication domain & $4.11 \pm 1.68$ & $4.12 \pm 1.53$ & 0.94 \\
\hline - Orgasm domain & $3.60 \pm 1.66$ & $3.33 \pm 1.62$ & 0.25 \\
\hline - Satisfaction domain & $4.10 \pm 1.49$ & $4.06 \pm 1.55$ & 0.86 \\
\hline - Pain domain & $3.32 \pm 1.12$ & $3.56 \pm 1.09$ & 0.13 \\
\hline Total FSFI & $21.93 \pm 7.05$ & $21.49 \pm 6.60$ & 0.64 \\
\hline
\end{tabular}

Table (3): Relation between pregnancy, sexual satisfaction, and FGM

\begin{tabular}{|c|c|c|c|c|c|}
\hline \multirow[t]{3}{*}{ Variables } & \multicolumn{4}{|c|}{ FGM } & \multirow{3}{*}{$P$-value } \\
\hline & \multicolumn{2}{|c|}{$\begin{array}{l}\text { Not Done } \\
(\text { No.=109) }\end{array}$} & \multicolumn{2}{|c|}{$\begin{array}{c}\text { Done } \\
(\text { No.=97) }\end{array}$} & \\
\hline & No. & $\%$ & No. & $\%$ & \\
\hline $\begin{array}{l}\text { Sexual satisfaction before pregnancy: } \\
\text { - Very satisfied }\end{array}$ & 14 & 12.84 & 10 & 10.30 & \multirow{5}{*}{0.53} \\
\hline - Satisfied & 16 & 14.67 & 22 & 22.68 & \\
\hline - Neutral & 8 & 7.33 & 5 & 5.15 & \\
\hline - Unsatisfied & 45 & 41.28 & 34 & 35.05 & \\
\hline - Very unsatisfied & 26 & 23.85 & 26 & 26.80 & \\
\hline $\begin{array}{l}\text { Sexual satisfaction during pregnancy } \\
\text { - Very satisfied }\end{array}$ & 10 & 9.17 & 10 & 10.30 & \multirow{5}{*}{0.91} \\
\hline - Satisfied & 21 & 19.26 & 21 & 21.64 & \\
\hline - Neutral & 12 & 11.01 & 13 & 13.40 & \\
\hline - Unsatisfied & 44 & 40.36 & 33 & 34.02 & \\
\hline - Very unsatisfied & 22 & 20.18 & 20 & 20.61 & \\
\hline
\end{tabular}




\section{الملخص العربي}

العلاقة بين تثويه الأعضاء التناسلية الأثتوية والضعف الجنسي أثناء الحمل : دراسة تجريبية

ايمان السيد ابراهيم ـ مروة مصطقي احمد 1 ـ رشا سعد الخولي 1 ـ مروة سيد سعيد1

1 قسم طب الاسرة- جامعه القاهرة

الخلفية: يعتبر الخلل الوظيفي الجنسي للإناث أحد العو اقب التي ينم تجاهلها و المرتبطة بتشبويه الأعضاء التناسلية الأنثوية

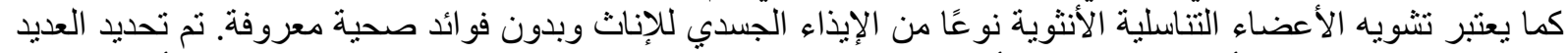

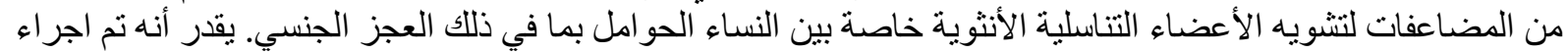

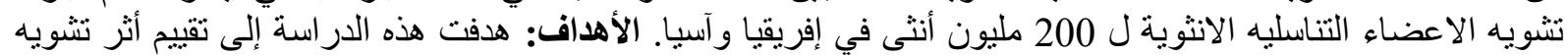

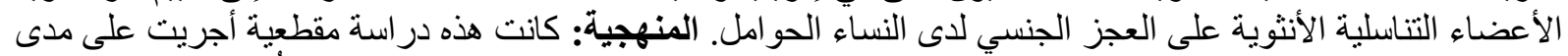

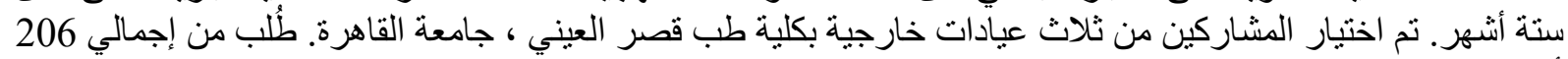

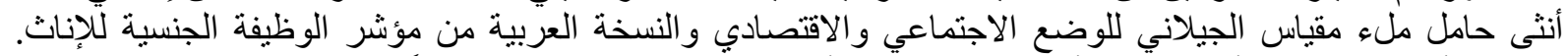

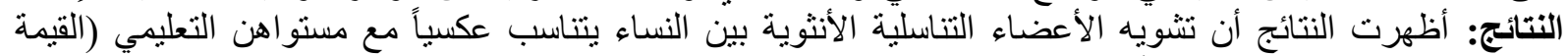

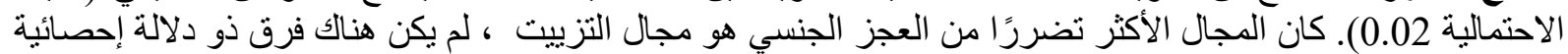

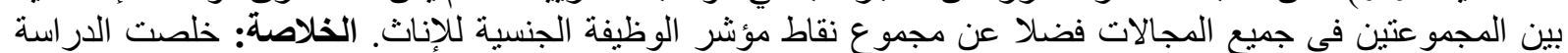

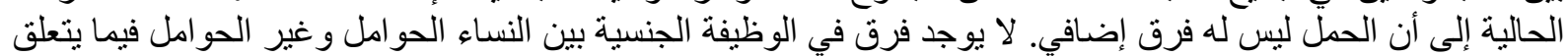

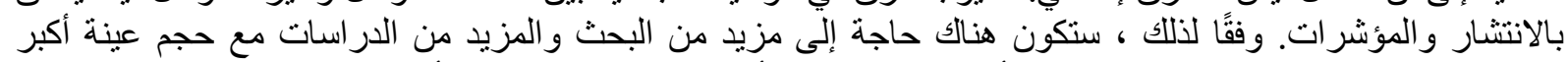

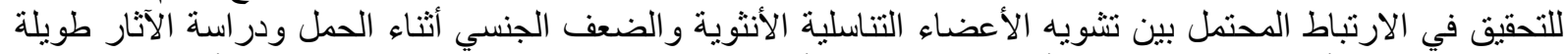

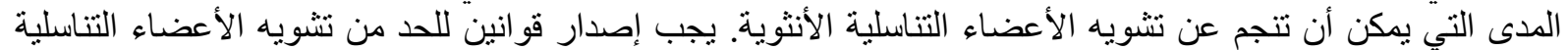

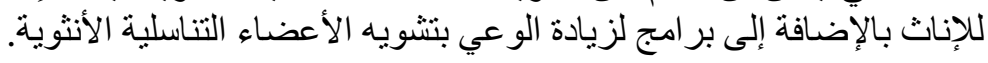

Egyptian Family Medicine Journal (EFMJ)

Vol .5(2), Nov. 2021

http://efmj.journals.ekb.eg/

@- (1) This article is an open access article distributed under the terms and conditions of the Creative Commons Attribution (CC BY) license (http://creativecommons.org/licenses/by/4.0/ 